Doutor em Direito pela Universidade de São Paulo; Humberto Theodoro Júnior; Professor Titular da Universidade Federal de Minas Gerais e Doutor em Direito pela mesma instituiçäo; Daniel Francisco Mitidiero, Professor da Universidade Federal do Rio Grande do Sul e Doutor em Direito pela mesma instituição. A referida defesa foi presidida pelo Professor Carlos Alberto Alvaro de Oliveira.

\title{
A Divisão Patrimonial na Dissolução da União Estável: Uma Interpretação das Regras de Direito de Família
}

Por Ana Rispoli D'Azevedo

Data da defesa da dissertação: 12/12/2007

Orientadora: Claudia Lima Marques

Essa dissertação objetiva analisar a divisão patrimonial, sob o enfoque da união estável, tendo em vista a especificidade do tratamento dado a esta entidade familiar na hipótese de dissolução. São estudadas as regras que incidem na divisão dos bens, quando da ruptura em vida da uniăo estável, seja consensual ou litigiosa, através da evolução doutrinária e jurisprudencial da matéria. Também se verifica a utilização de regras do direito matrimonial no companheirismo pelos aplicadores da lei e suas conseqüências. Em suma, o tema proposto tem por fim estabelecer a relação entre o desenvolvimento da matéria, ao longo dos anos, pelos Tribunais, pela Doutrina e pelo Legislativo, assim como a determinação consagrada no Código Civil de 2002.

A banca examinadora foi composta pelos Professores: Giselda Maria Fernandes Novaes Hironaka, Professora da Universidade de São Paulo e Doutora em Díreito pela mesma instituição; Carlos Silveira Noronha, Professor da Universidade Federal do Rio Grande do Sul e Doutor em Direito pela Universidade de São Paulo; José Alcebíades de Oliveira Júnior, Professor da Universidade Federal do Rio Grande do Sul e Doutor em Direito pela Universidade Federal de Santa Catarina. A referida defesa foi presidida pela Professora Doutora Claudia Lima Marques.

\section{A Responsabilidade Internacional do Estado por Genocídio}

Por Joanessa Tasca Deud Jose

Data da defesa da dissertação: 17/12/2007

Orientadora: Martha Lucía Olivar Jimenez 
Trata-se de estudo sobre a configuração da responsabilidade internacional de ente estatal por genocídio, tomando como ponto de partida as regras gerais da responsabilidade do Estado e a decisão proferida em 26 de fevereiro de 2007 pela Corte Internacional de Justiça no caso envolvendo a Bósnia e a Sérvia - a primeira decisão na história da jurisprudência internacional que tratou especificamente da matéria.

A banca examinadora foi composta pelos Professores Doutores: Véra Maria Jacob De Fradera, Professora da Universidade Federal do Rio Grande do Sul e Doutora em Direito pela Universite de Paris II Up II, PARIS II, França; Alfa Oumar Diallo, Professor do Centro Universitário La Salle e Doutor em Sociedade e Estado em Perspectiva de Integração pela Universidade Federal dó Rio Grande do Sul; Denise Estrella Tellini, Professora da Universidade Luterana do Brasil e Doutora em Estudios Internacionales pela Universidade de Barcelona. A referida defesa foi presidida pela Professora Martha Lucía Olivar Jimenez.

Outras Dissertações de Mestrado Defendidas Junto ao Programa de Pós-Graduação em Direito durante o Ano de 2007

A Verossimilhança nos Provimentos de Cognição Sumária

Por Daisson Flach

Data da defesa da dissertação: 12/01/2007

Orientador: Carlos Alberto Alvaro de Oliveira

Banca examinadora: Ovídio Araújo Baptista da Silva, da Universidade do Vale do Rio dos Sinos e Livre Docente pela Universidadé Federal do Rio Grande do Sul; Danilo Knijnik, da Universidade Federal do Rio Grande do Sul e Doutor em Direito pela Universidade de São Paulo; Guilherme Rizzo Amaral, da Pontificia Universidade Católica dó Rio Grande do Sul e Doutor em Direito pela Universidade Federal do Rio Grande do Sul.

o Pluralismo Jurídico e a Realidade Sociocultural de Moçambique Por Beatriz da Consolação Mateus Buchili

Data da defesa da dissertação: 01/03/2007

Orientadora: Cláudia Lima Marques 